\section{FAILURE TO DEMONSTRATE CIRCULATING ANTIBODY TO ALCOHOLIC BRAIN EXTRACTS IN MULTIPLE SCLEROSIS}

\author{
BY
}

IAN MACLEOD, M.B., B.S.

ALAN R. RIDLEY, M.B., M.R.C.P.

CATHERINE SMITH,

\author{
Technical Assistant
}

AND

E. J. FIELD, M.D., Ph.D., M.S.

From the Medical Research Council Group on Demyelinating Diseases and Department of Pathology, Royal Victoria Infirmary and King's College, Newcastle upon Tyne

Since Sachs and Steiner (1934) claimed to have demonstrated complement-fixing antibodies to brain in the serum of multiple-sclerosis patients, attempts to confirm and extend their findings have resulted in sharply divided conclusions. Some have agreed, culminating in the report by Raskin (1955), who has reported almost double their percentage of positives; others, however, have not been able to find such antibodies at all. To decide between these conflicting observations is obviously important in the study of the pathogenesis of multiple sclerosis, especially since a humoral myelotoxic factor has recently been described in serum from animals with experimental allergic encephalitis (Bornstein and Appel, 1959).

The present work was originally planned to follow the method of Raskin (1955), who has reported the greatest success, but this was quickly found to lead to technical difficulties in that results, both positive and negative, were not reproducible. Use of completely fresh (unfrozen) sera did not remove these inconsistencies, and a detailed examination of the methods used by various authors was therefore made. As a result we believe that, to a considerable degree, discrepancies can be traced to variations in technical method; of these, differences in the amount of complement used is the most important.

\section{Materials}

Sheep cells: Burroughs Wellcome formol-preserved. Buffered saline: Brook's physiological buffered saline (Kellett, 1954). Brain extract: Brain which had been fixed in $10 \%$ formol for some months was cleared of membranes and vessels, washed in running tap-water for several weeks, dried, powdered, mixed with absolute alcohol ( $1 \mathrm{~g}$. of powder to $5 \mathrm{ml}$. of alcohol), and allowed to extract for 12 days, being shaken by hand each day for a few minutes and finally centrifuged for 20 minutes at 2,000 r.p.m. The clear supernatant, diluted with physiological buffered saline, gave a colloidal suspension analogous to a Wassermann antigen. Complement: Burroughs Wellcome normal guinea-pig serum preserved by Richardson's (1941) method. Haemolytic serum: Burroughs Wellcome rabbit anti-sheep red corpuscle haemolytic serum.

\section{Methods}

1. Sheep cells were washed three times in buffered saline; the packed cell volume was measured with Hawkesley micro-haematocrit and diluted to 5\%. This suspension was mixed with an equal volume of haemolytic serum in a dilution which provided 5 M.H.D., and incubated at $37^{\circ}$ C. for 30 minutes, giving a final suspension of $2.5 \%$ sensitized cells.

2. Complement Titration.-An arithmetic series of complement dilutions in steps of five covering the range from " $100 \%$ haemolysis" to " no detectable haemolysis" was made. To $0.5 \mathrm{ml}$. of each dilution $1 \mathrm{ml}$. of sensitized cells was added. After 30 minutes' incubation the tubes were centrifuged (1.000 r.p.m. for 10 minutes at $14^{\circ} \mathrm{C}$.) and $0.8 \mathrm{ml}$. of the supernatant was transferred as quickly as possible to $5 \mathrm{ml}$. of Drabkin's cyanide-ferricyanide solution (Dacie, 1956). Absorption due to cyanmethaemoglobin was measured in an E.E.L. colorimeter using the built-in yellow-green filter. Using standards prepared from the original cell suspension, a haemolysis curve was plotted and the $50 \%$ haemolytic unit $\left(\mathrm{MHD}_{50}\right)$ of complement calculated. Because of the sigmoid shape of the haemolysis curve, the $\mathrm{MHD}_{50}$ can be determined more precisely than the $\mathrm{MHD}_{100}$, and so was preferred; five such units were used in the tests as recommended by Kabat and Mayer (1961) " to eliminate or to reduce to a minimum false positive reactions which may arise from a variety of technical factors." Among this "variety" a serious hazard is the simulation of complement fixation by the summation of anticomplementary properties in serum and antigen which individually are too weak to inhibit the controls. Having more than the theoretical minimum amount of complement present ensures that the test errs on the side of caution.

3. Antigen.-The alcoholic brain extract was placed in a dry beaker, buffered saline being added rapidly to produce a colloidal suspension. The antigen dilution to be used in the test (usually in the range 1/200-1/1000) was titrated with a series of complement dilutions increasing in steps of $0.5 \mathrm{MHD}_{50} ; 0.5 \mathrm{ml}$. of antigen, $0.5 \mathrm{ml}$. of complement dilution, and $0.5 \mathrm{ml}$. of buffered saline were incubated for an hour ; $0.5 \mathrm{ml}$. of sensitized cells was added and incubated for a further 30 minutes; after spinning, haemolysis was measured and from the result the amount of complement sufficient to counteract any anticomplementary activity of the antigen calculated. This "extra" complement was added to the $5 \mathrm{MHD}_{50}$ in the tests, thus ensuring that they contained not less than 5 and not more than $5.5 \mathrm{MHD}_{50}$ in the presence of the antigen. The serum control contained only $5 \mathrm{MHD}_{50}$ of complement ; sera anticomplementary enough to inhibit haemolysis in this control were not tested further.

4. Test $-0.5 \mathrm{ml}$. of inactivated serum $\left(56^{\circ} \mathrm{C}\right.$. for 30 minutes), $0.5 \mathrm{ml}$. of diluted complement, and $0.5 \mathrm{ml}$. of diluted brain extract were incubated for one hour; $0.5 \mathrm{ml}$. of sensitized cells was added and the tubes incubated for a further 30 minutes, centrifuged, and haemolysis in the supernatant measured as before. A positive result was recorded if there was more than $50 \%$ haemolysis in the "serum control" tube and inhibition of haemolysis in the test. Results of this kind were obtained with the alcoholic multiple-sclerosis brain extract and rabbit anti-human brain sera produced by immunization. A negative result was recorded if there was more than $50 \%$ haemolysis in "serum control" and test-tubes.

Sera tested were from all stages of the disease in patients encompassed by the North-East multiplesclerosis survey under the direction of $\mathrm{Dr}$. H. G. Miller: 23 were from 18 cases of acute exacerbations 
of the disease admitted to hospital for therapeutic trial ; 97 sera were from 92 chronic cases. Altogether 120 serum specimens were tested from the 110 patients. Seventy multiple-sclerosis spinal fluids were examined and 34 control specimens. Control sera were from cases of epilepsy, cerebral arteriopathy, cerebral tumour, various skin diseases, and normal people. Control spinal fluids were from the same sort of cases (but none from normal people was available).

\section{Results}

Using the $5 \mathrm{MHD}_{50}$ method (in which we felt more confidence could be placed than in the $2 \mathrm{MHD}_{100}$ ) we obtained no result indicating complement fixation with either serum or cerebrospinal fluid.

\section{Discussion}

The validity of the results of the complement-fixation test hangs upon the use of adequate controls and a due regard for factors which may lead to non-specific complement deviation. The anticomplementary nature of lipid-rich organ extracts has long been known (Landsteıner and von Eisler, 1907). Sachs and Steiner (1934) recognized the anticomplementary properties of brain extracts, especially those made from formol fixed material, and diluted the antigen to an acceptable level of anticomplementary activity; sera were reckoned positive when they brought about additional complement fixation. Most workers since their time have encountered this anticomplementary activity of alcoholic extracts of brain, especially when prepared from material long fixed in formol, and Delank (1957) sought to counteract it (as we did) by the appropriate addition of guinea-pig complement.

Some observers-for example, Lumsden et al. (1950) - have remarked how often the serum of multiplesclerosis patients is anticomplementary, a finding which we amply confirm. Raskin (1955) records no example in 120 patients and only one in 60 controls. Like Lumsden et al., we feel that this characteristic of the serum enhances the danger of false-positive reactions when the test employs minimal amounts of complement.

The usual controls were employed to exclude inhibitory or haemolytic activity of the saline diluent, haemolytic activity of the antigen, and malfunction of the haemolytic system, but the "positive control" considered essential in routine complementfixation tests presented a difficulty: when searching for an unknown or possibly non-existent antibody no positive control exists. As second best, we tested our system with an immune rabbit anti-human brain serum, and while this was not strictly analogous to the postulated human serum factor it showed that, given an antibody, the test worked.

Attention has recently been drawn to the importance of the initial complement level in the complementfixation tests by Goudie et al. (1959) with reference to the occurrence of false-positive complement-fixation tests in Hashimoto's disease. They emphasize the need for an adequate level of complement in excess of the sum of the anticomplementary activities of the serum and organ extract in each tube. Such caution is not, unfortunately, shown in much of the work which purports to demonstrate a frequent occurrence of brain antibodies in multiple-sclerosis serum. The results of tests on sera when $2 \mathrm{MHD}_{100}$ of complement was used (Raskin, 1955) were, in our hands, apparently randomly spread among patients and controls and non-reproducible. Curiously enough, those from examination of C.S.F. were statistically significant (at the $5 \%$ level), though, as in the case of serum, they became consistently negative when the amended method was employed. The most carefully controlled work-for example, that of Lumsden et al. (1950)-has been consistently negative; with this finding our own results are in complete agreement.

It is not always easy to find a clear statement of the amount of complement used. Thus Frick (1954), who reports 25 out of 50 cases of multiple-sclerosis positive, as against 3 out of 50 controls from other neurological diseases, states that the complement-fixation test was carried out "in the usual way." Bauer and Heitmann (1958) used the "usual controls." They found only 5 out of 62 patients positive $(8 \%)$ while 2 out of 105 controls $(1.9 \%)$ were also positive.

The significance of positive results, even if firmly established, would be difficult to assess. The reported occurrence of antibodies to brain in amyotrophic lateral sclerosis (Roemer et al., 1953) and after insulin convulsion therapy (Read et al., 1939) suggests that, if genuine, it may be secondary to destruction of myelin. However, we were unable to find any such antibodies in six patients at intervals from three weeks to three months after serious brain injury.

Some authors, however, claim to have shown a very attractive association between the severity of the disease and the titre of antibodies in the serum. Thus Frick (1951) claims that regression of clinical signs is accompanied by a reduced titre of circulating antibody which may even disappear. This, he says, occurs " mit grosser Regelmässigkeit," and concludes that a positive result is highly specific for the disease. However, he goes on to point out, as did Sachs and Steiner (1934), that many florid and progressive cases are seen which nevertheless show no antibodies on repeated examination. Roemer et al. (1953) found that three out of six cases of amyotrophic lateral sclerosis showed antibodies to brain. These authors reported circulating antibody in about $50 \%$ of clinically certain multiple-sclerosis patients, in $3.1 \%$ of other neurological conditions, and in almost $10 \%$ of a control group of various " internal diseases."

It is curious that positive results in the spinal fluid have not been so commonly reported as with serum, especially as it is now generally accepted that the gamma-globulin concentration is raised, though the significance of this has recently been questioned (Field and Ridley, 1960). While Sachs and Steiner (1934) found 3 out of 16 positive in undoubted multiple sclerosis, Frick (1951), who, as noted above, attaches diagnostic importance to the demonstration of antibodies, found none in the spinal fluid. We found that spinal fluids which gave positive results with $2 \mathrm{MHD}_{100}$ of complement gave uniformly negative results with the $5 \mathrm{MHD}_{50}$ method.

Our findings, together with those of Lumsden et al. (1950), Kolb (1950). Ahrengot (1957), and Broman et al. (1960), stand in opposition to those of many workers who have obtained evidence of circulating antibody to alcoholic extracts of brain in multiple sclerosis. Nevertheless, it cannot be asserted on negative evidence that no circulating antibody exists, merely that it has not been shown to exist; and it is possible that the application of a more sensitive test may succeed, as in the 
case, for example, of the skin-sensitizing antibody to ragweed extract (Stavitsky and Arquilla, 1955 ; Sehon, 1959). Evidence available at the moment, however, does not suggest that circulating antibody to brain plays any fundamental pathogenic part in multiple sclerosis.

\section{Summary}

Blood serum and spinal fluid from cases of multiple sclerosis in all stages of the disease and from controls (mainly other neurological conditions) failed to fix complement with an alcoholic brain extract when $5 \mathrm{MHD}_{50}$ of complement was used. The possible causes of discrepant reports in the literature are briefly discussed.

\section{References}

Ahrengot, V. (1957). Acta psychiat, scand. 32, 192.

Bauer, H., and Heitmann, R. (1958). Dtsch. Z. Nervenheilk. 178. 47.

Bornstein, M. B., and Appel, S. H. (1959). Trans. Amer. neurol. Ass., 84, 165.

Broman, T., Lidvall, H., Lind, A., and Meyer, P. (1960). Acta psychiat. scand., 35, 403.
Dacie, J V. (1956). Practical Haematology, 2nd ed. Churchill, London.

Delank, H. W (1957). Arch. Psychiat. Nervenkr., 195, 383.

Field, E. J., and Ridley, A. (1960). Brit. med. J., 2, 1053

Frick, E (1951). Dtsch. Z. Nervenheilk., 166, 54.

(1954). Klin. Wschr., 32, 450.

Goudie, R. B., Anderson, J. R., and Gray, K. G. (1959). J. Path. Bact., 77, 389.

Kabat, E. A., and Mayer, A. A. (1961). Experimental Immuno$\log y$, 2nd ed. Thomas, Illinois.

Kellett, C. E. (1954). Ann. rheum. Dis., 13, 211.

Kolb. L. C. (1950). Medicine (Baltimore), 29, 99.

Landsteiner, K., and von Eisler, H. (1907). Wein klin. Wschr. 20, 1565

Lumsden, C. E., Kabat, E. A., Wolf, A., and Bezer, A. E. (1950). J. exp. Med., 92, 253 .

Raskin, N. (1955). Arch. Neurol. Psychiat. (Chic.), 73, 645.

Read, C. F., Heilbrunn, G., and Leibert, E. (1939). J. nerv. ment. Dis., 90.747.

Richardson, G. M. (1941). Lancet, 2, 696.

Roemer, G. B., Schrader, A., and Schild, W. (1953). Klin. W schr., 31, 946.

Sachs, H., and Steiner, G. (1934). Ibid., 13, 1714

Sehon, A. H. (1959). In Mechanisms of Hypersensitivity, edited by J. H. Shaffer, G. A. Lo Grippo, and M. W. Chase. Churchill, London.

Stavitsky, A. B., and Arquilla, E. R. (1955). J. Immunol., 74, 306.

\title{
MULTIPLE SCLEROSIS AND SPINAL-FLUID GAMMA-GLOBULIN
}

\author{
BY \\ J. B. FOSTER, M.B., M.R.C.P. AND $\quad$ D. B. HORN, Ph.D., F.R.I.C. \\ From the Departments of Clinical Chemistry and Neurology, the Royal Victoria Infirmary and the \\ Medical School, Newcastle upon Tyne
}

Although its origin and pathological significance remain uncertain, many workers have confirmed that the gamma-globulin fraction of the spinal-fluid protein is often strikingly increased in multiple sclerosis (Kabat et al., 1942, 1950 ; Roboz et al., 1953 ; Yahr et al., 1954 ; Ivers et al., 1961 ; Schapira and Park, 1961).

The application and limitations of this method of investigation were discussed by Schapira and Park, who found a mean level of $22.4 \%( \pm 9.47)$ of gammaglobulin expressed as a fraction of total spinal-fluid protein in 81 patients with multiple sclerosis, as compared with a figure of $11.1 \%( \pm 3.18)$ in 25 control cases: they estimated gamma-globulin by an electrophoretic method, and the increase in this fraction in the cases of multiple sclerosis was highly significant $(P<0.001)$. Schapira and Park shared the views of those who had previously reported observations on smaller series of cases that the estimation was potentially helpful in diagnosis.

However, electrophoretic estimation of spinal-fluid proteins is laborious and beyond the scope of smaller laboratories. Papadopoulos et al. (1959) described a simple colorimetric method of estimation based on the use of the Folin-Ciocalteu (1927) phenol reagent. It was decided to test this method on the spinal fluids of consecutive neurological admissions to try to assess the comparative value of this very much simpler laboratory test.

Material.-The spinal fluids obtained from 200 successive admissions were first examined by routine laboratory methods, and the total protein and the gamma-globulin were estimated by the method of Papadopoulos et al. From a total slightly in excess of 200 a few cases were excluded in which diagnosis remained uncertain.

\section{Results}

In all cases the gamma-globulin level was expressed as a percentage of total protein, the value of which ranged from 19 to $500 \mathrm{mg} . / 100 \mathrm{ml}$ of cerebrospinal fluid. The figures for some of the main groups of patients are given in Table 1 ; cases of multiple sclerosis were regarded as "acute" when symptoms had been present for less than one month.

TABLE I.-Spinal-fluid Gamma-globulin Levels in Eight Common Neurological Disorders

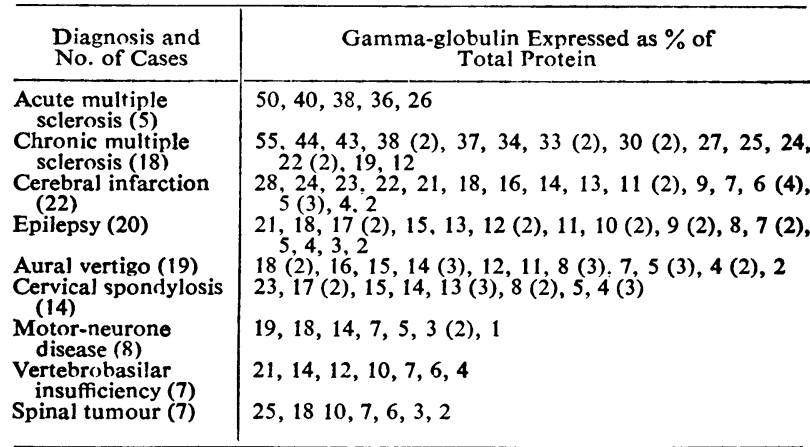

Among smaller groups of patients were six with miscellaneous headaches $(16,9,6,6,5,3)$; five each with neurosyphilis $(47,32,31,14,11)$, chronic polyneuritis $(17,12,11,6,3)$, and carotid artery stenosis $(30,21,19,13,7)$. There were four each with presenile dementia $(26,16,6,5)$ and cerebral glioma $(29,26,25$, $12)$; and three cases of retrobulbar neuritis $(37,18,15)$, spontaneous subarachnoid haemorrhage. $(23,11,2)$, Guillain-Barré syndrome $(18,14,14)$, and hypertensive cerebral haemorrhage $(13,6,3)$.

The series comprised two cases each of benign intracranial hypertension (11, 9), Krabbe's leucodystrophy $(18,16)$, syringomyelia $(9,5)$, subacute combıned degeneration $(8,5)$, aqueduct stenosis $(18,17)$, temporal arteritis $(19,18)$, paralysis agitans $(18,6)$, cerebellar degeneration $(23,7)$, cerebral fat embolism $(11,9)$, and haemophilus meningitis $(27,3)$. Single cases gave figures as follows: subacute inclusion-body encephalitis (33), Stokes-Adams attacks (6), post-pertussis atrophy of cerebral hemisphere (20), migraine (8), syncope (11), progressive myoclonic epilepsy (12), recent poliomyelitis 